\title{
Assaying Total Carotenoids in Flours of Corn and Sweetpotato by Laser Photoacoustic Spectroscopy
}

\author{
Svjetlana Luterotti • Dane Bicanic • Kristina Kljak • \\ Darko Grbesa • Eduardo San Martin Martínez • \\ Ruud Spruijt
}

Published online: 17 July 2010

(C) The Author(s) 2010. This article is published with open access at Springerlink.com

\begin{abstract}
This study describes the application of the laser photoacoustic spectroscopy (PAS) for quantification of total carotenoids (TC) in corn flours and sweetpotato flours. Overall, thirty-three different corn flours and nine sweetpotato flours were investigated. All PAS measurements were performed at room temperature using 488-nm argon laser radiation for excitation and mechanical
\end{abstract}

This work was presented in part at 6th International Conference: Instrumental Methods of Analysis-Modern Trends and Applications, 4-8 October 2009, Athens, Greece.

This research is partly financed by the research grants of the Ministry of Science, Education and Sports, Republic of Croatia: "Interactions of gallium(III) and iron(III) with antiproliferative drugs" (0060061117-1243) and "Nutritional, antioxidative and prebiotic attribute of corn for domestic animals" (178-1780496-0368). The authors thank the Faculty of Agronomy, University of Zagreb, for donating some species of corn flours.

S. Luterotti $(\bowtie)$

Faculty of Pharmacy and Biochemistry, University of Zagreb,

A. Kovačića 1,

10000 Zagreb, Croatia

e-mail: sluter@pharma.hr

D. Bicanic $\cdot$ R. Spruijt

Laboratory of Biophysics, Wageningen University,

Dreijenlaan 3-Transitorium,

6703 HA Wageningen, The Netherlands

K. Kljak $\cdot$ D. Grbesa

Faculty of Agronomy, University of Zagreb,

Svetošimunska 25,

10000 Zagreb, Croatia

\section{E. S. Martínez}

Centro de Investigacion en Ciencia Aplicada

y Tecnologia Avanzada,

IPN, Legaria 694, Colonia Irrigacion,

11500 Mexico, DF, Mexico modulation of 9 and $30 \mathrm{~Hz}$. The measurements were repeated within a run and within several days or months. The UV-Vis spectrophotometry was used as the reference method. The concentration range that allows for the reliable analysis of TC spans a region from 1 to $40 \mathrm{mg} \mathrm{kg}^{-1}$ for corn flours and from 9 to $40 \mathrm{mg} \mathrm{kg}^{-1}$ for sweetpotato flours. In the case of sweetpotato flours, the quantification may extend even to $240 \mathrm{mg} \mathrm{kg}^{-1} \mathrm{TC}$. The estimated detection limit values for TC in corn and sweetpotato flours were 0.1 and $0.3 \mathrm{mg} \mathrm{kg}{ }^{-1}$, respectively. The computed repeatability $(n=3-12)$ and intermediate precision $(n=6-28)$ RSD values at 9 and $30 \mathrm{~Hz}$ are comparable: $0.1-17.1 \%$ and $5.3-14.7 \%$ for corn flours as compared with $1.4-9.1 \%$ and $4.2-23.0 \%$ for sweetpotato flours. Our results show that PAS can be successfully used as a new analytical tool to simply and rapidly screen the flours for their nutritional potential based on the total carotenoid concentration.

Keywords Photoacoustic spectroscopy (PAS) .

Total carotenoids assay $\cdot$ Corn flours · Sweetpotato flours

\section{Introduction}

Photoacoustic spectroscopy (PAS) relies on the indirect measurement of absorbance in the optically thin, as well as in the opaque and light scattering media. This makes PAS a unique method in the comparison with conventional spectroscopy where the specimen's transparency is an absolute necessity. In addition, PAS is simple to use, requires only a small quantity of sample for analysis, involves a minimum of preparation (samples are studied just as they are), and is also less susceptible to the reflectance and morphology of the sample. 
The basic principle behind the PAS is the generation of pressure as a result of the heat induced in the absorbing condensed phase sample when the latter is exposed to a periodically modulated or pulsed radiation of selective wavelength. ${ }^{1-3}$ Such periodic heating and cooling at acoustic frequencies leads to the production of oscillating pressure in the volume of air (called PA cell) above the sample. The amplitude of pressure is detected (at the modulation frequency $f$ ) by means of a transducer such as for example a microphone. For a given incident power of the excitation source, the modulation frequency $f$, and the specific PA cell, the strength of the PA signal is, in the absence of saturation, directly proportional to the concentration of the absorbing analyte. ${ }^{4-6}$

When combined with a laser as an intense excitation source, the concept of PAS detection has already proven an effective analytical method for the quantification of lutein in biological matrix, ${ }^{7}$ lycopene in the tomato based products, ${ }^{8,9}$ and total carotenes in various margarine matrices. ${ }^{10}$

This study is concerned with the application of the laser based PAS to powdered food samples. In particular, the method was used to determine the total carotenoid (TC) concentration in a large number of corn and sweetpotato flours. Both flours contain carotenoids the consumption of which has often been linked to a diversity of health beneficiary effects in humans. ${ }^{11}$ The concentration of carotenoids in the sweetpotato flour is high with $\beta$-carotene being a dominant compound. Sweetpotato flour can also be promoted as a substitute for corn flour; however, its price is higher than that of the corn flour. ${ }^{12-14}$ Some of the PA studies previously performed on flours included: (1) the analysis of a blue corn pigment in nixtamalized flours, ${ }^{15}$ (2) monitoring the processing conditions in cooked tortillas, ${ }^{16}$ (3) determination of iron in corn meals, ${ }^{17}$ (4) the quantification of phenolics in red sorghum flours, ${ }^{18}$ etc.

\section{Materials and Methods}

\section{Samples}

Thirty-three corn flours (in the forthcoming text abbreviated as $\mathrm{CF}$ ) were obtained either from the grocery stores in Croatia or provided by the Faculty of Agronomy, University of Zagreb, Croatia. The precooked white corn flour ( $\mathrm{CF} 0$ ), which served as the blank sample, was a commercial product of Refinadora de Maiz Venezoloana, C.A. (Remavenca), La Encrucijada de Turmero, Edo. Aragua, Venezuela. The nine sweetpotato flours (abbreviated SPF) were obtained from Mexico (provided by one of the authors) and Kenya (kindly donated by Ulla Kidmose, Department of Food Science, Faculty of Agricultural Sciences, Aarhus University, Aarhus, Denmark).

\section{Size Distribution Analysis}

Malvern Mastersizer 2000 laser diffractometer was used to analyze the size of the particles and their distribution. The measurements of particulate material (as dispersion in ethanol) in five flours (within the span of 0.02 to $2,000 \mu \mathrm{m}$ ) were performed by Jos Sewalt (Wageningen University). The investigated flours included two yellow corn flours: CF2 (18.12 $\left.\mathrm{mg} \mathrm{kg}^{-1} \mathrm{TC}\right)$ and CF4 (10.33 mg kg ${ }^{-1} \mathrm{TC}$ ), pre-cooked white corn flour CF0 $\left(0.13 \mathrm{mg} \mathrm{kg}^{-1} \mathrm{TC}\right)$, and sweetpotato flours SPF2 (38.8 $\left.\mathrm{mg} \mathrm{kg}^{-1} \mathrm{TC}\right)$ and SPF1 $\left(0.3 \mathrm{mg} \mathrm{kg}{ }^{-1} \mathrm{TC}\right)$; the TC was assayed spectrophotometrically.

\section{PA Measurements Experimental Setup and Conditions}

The PA measurements on flours were performed at a room temperature using the home-made experimental setup. The 488-nm radiation emitted by the free-running cw Ar-ion laser (model LEXEL-85) was used for the excitation of carotenoids. Its output power measured at the laser head with Spectra Physics 407A detector was typically between 90 and $100 \mathrm{~mW}$. From this power, some 70 to $74 \mathrm{~mW}$ eventually reached the flour in the PA cell. The long-term power stability of the laser was better than $1 \%$. The modulation (at either 9 or at $30 \mathrm{~Hz}$ ) of the laser beam intensity was achieved by means of the SR450 mechanical chopper controller (Stanford Research Systems Inc.) equipped with the slotted blade.

Major components of the non-resonant, home-made PA cell include the entrance window made from Suprasil, an "O" ring, the KE 4-211-2 electret microphone from Senheiser, and the sample tray. This latter is actually a stainless steel plate $(40 \mathrm{~mm}$ in diameter) provided with a central, semispherical cavity (diameter $8 \mathrm{~mm}$, volume about $0.25 \mathrm{~cm}^{3}$ ) used to accommodate the flour specimen. A tube, $15 \mathrm{~mm}$ long and $1 \mathrm{~mm}$ in diameter, provided the acoustical coupling between this air volume and the microphone. The output of the microphone was preamplified and connected to the input of the two-phase lock-in amplifier EG\&G 5101; the detection of the lock-in voltage (i.e., PA signal) took place at the modulation frequency using the integration constant of $1 \mathrm{~s}$.

A small spatula was used to load the flour into the sample tray; the excessive quantity was removed by carefully flattening/smoothing the flour surface while at the same time paying maximal attention not to compress the flour. ${ }^{18}$ The volume of the air space between the surface of the sample and the rear side of the entrance window was 
$0.22 \mathrm{~cm}^{3}$. Since particulate material such as the flour is in general easily compressed even when exposed to a slight external force, care was exercised during the loading procedure in order to have highly reproducible samples for the PA measurements. Changes in the compaction (the flour becomes more dense) may on their turn affect flour's optical properties, as it will be discussed later. ${ }^{19}$ Because of the observed gradual, continuous decrease of PA signal during the irradiation of the sample by the laser beam, a well-defined measuring protocol was proposed and used consistently to quantify total carotenoids in flours. With a tray loaded and placed in a proper position, the laser radiation was blocked for $10 \mathrm{~s}$ during which the PA signal on the lock-in amplifier reached the zero value. The laser radiation was then unblocked for another $10 \mathrm{~s}$ to allow the PA signal to stabilize at its end level. From this very moment the magnitude of PA signal was monitored for the following $15 \mathrm{~s}$ and data obtained used for the statistical analysis. The PA measurements on a given flour sample were repeated within a run and for some samples also within several days or even months later. For a single sample of corn flour, this has resulted in the total of 3 to 28 measurements at $9 \mathrm{~Hz}$ and 3 to 21 measurements at $30 \mathrm{~Hz}$. After calculating the mean for each set of within-a-run measurements and for 33 corn flour samples, one arrives to overall 52 experimental data at $9 \mathrm{~Hz}$ and 55 experimental data at $30 \mathrm{~Hz}$. In the case of sweetpotato flours, three to ten repetitive PA measurements were performed with each sample yielding total of 14 and 12 data points at 30 and $9 \mathrm{~Hz}$, respectively. Between the successive measurements, the sample cavity was cleaned with ethanol.

The estimated detection limit $(D L)$ for PA analyses is defined as the lowest concentration level at which the analyte can still be reliably detected. This estimate was based on the visual evaluation and proven by comparison with the signal obtained from the blank sample. ${ }^{20}$

\section{PA Measurements Principles and Criteria}

It is a widely accepted practice to normalize the experimentally obtained PA signals. The normalization step requires the knowledge of the PA signals obtained (under identical experimental conditions: wavelength, laser power, modulation frequency, PA cell, and geometry used) from a fine carbon black (CB) powder that acts as a strongly absorbing reference. The normalized PA signals are nedeed to calculate, from the experimental data, the characteristic dimensionless product $\beta \times \mu$, an important quantity in the PA measurements. The symbols $\beta$ (the absorption coefficient per unit length) and $\mu$ (thermal diffusion length that is frequency dependent, see below for definition) are related to optical and thermal properties of the sample under investigation. The conductive transfer of thermal energy, which is a major mechanism responsible for the generation of PA signal in the powdered samples, is a very complex process. The magnitude of the PA signal depends on the factors such as the incident power of the excitation source, the concentration of the absorbing compound (directly related to $\beta$ ), the modulation frequency (that influences $\mu$ ), the shape and the size of the particle, etc. ${ }^{21}$ Generally, it was observed that the PA signal decreases with the increasing particle's size. ${ }^{22}$ Due to a possible expansion of the interstitial gas, ${ }^{4}$ the role of an extra pressure term should, next to the usual thermal term (associated with the heat transfer from the sample to the gas), also be considered in the generation process of the PA signal in powdered samples. For larger particles, the surface area to volume ratios due to the scattering are lower than in case of smaller ones. Consequently, an improved thermal contact between the flour particle and air leads to a higher PA signal in smaller particles samples.

It was Rosencwaig who derived the mathematical expression for the magnitude of PA signal as a function of the above stated parameters. ${ }^{1}$ Depending on the relative magnitudes of the sample's physical thickness $L$, the optical penetration depth $1 / \beta$, and the thermal diffusion length $\mu$, six particular cases, each with its own approximate mathematical expression for the strength of the PA signal, have been proposed. For example, if the condition $L>1 / \beta>\mu$ is met (this is the case of a thermally thick and optically thick sample), the amplitude of the PA signal is expected to be linearly proportional to the product $\beta \times \mu .^{23}$

Before carrying out the actual PA experiments on flours, an attempt was made to obtain more insight about the validity of condition $\beta \times \mu<1$ for the flours. As far as $\beta$ is being concerned, it is generally known that a degree of particle compaction (packing density) has a pronounced effect on the magnitude of flour's $\beta$. In the recently performed time of flight spectroscopic study in the wavelength region between $650 \mathrm{~nm}$ and $1100 \mathrm{~nm}$, the value $\beta=2.3 \mathrm{~cm}^{-1}$ (at $700 \mathrm{~nm}$ ) reported for uncompressed flour is about 16 times larger than $\beta$ obtained for compacted flour. ${ }^{19}$ For the flours investigated in this study, $\beta$ values can be estimated by considering the approach similar to that proposed by Belton and Tanner. ${ }^{24}$ Assuming $2.0 \times 10^{5} 1 \mathrm{~mol}^{-1} \mathrm{~cm}^{-1}$ for the molar absorptivity of beta carotene at $490 \mathrm{~nm}$ and 536.87 as a relative molecular mass of the same compound, one obtains $\beta=17.8 \mathrm{~cm}^{-1}$ for uncompressed corn flour CF1 (TC concentration $33.42 \mathrm{mg} \mathrm{kg}^{-1}$ ). This value of $\beta$ is equivalent to the optical penetration depth $1 / \beta$ of about $5.62 \times 10^{-2} \mathrm{~cm}$ $(562 \mu \mathrm{m})$. On the other hand, thermal diffusion length $\mu$ in flour at a given modulation frequency $f$ can be readily calculated from the relationship $\mu=(\alpha / \pi f)^{1 / 2}$ provided thermal diffusivity $\alpha$ is known. With $\alpha=15.5 \times 10^{-8} \mathrm{~m}^{2} \mathrm{~s}^{-1}$ as a representative value for thermal diffusity of the corn flour, ${ }^{25,26}$ one obtains $7.41 \times 10^{-3} \mathrm{~cm}(74.1 \mu \mathrm{m})$ and $4.06 \times$ $10^{-3} \mathrm{~cm}(40.6 \mu \mathrm{m})$ for thermal diffusion length at 9 and 
Table 1 The distribution of grain size in several flours

\begin{tabular}{lccc}
\hline Flour code & $d(0.1)(\mu \mathrm{m})$ & $d(0.5)(\mu \mathrm{m})$ & $d(0.9)(\mu \mathrm{m})$ \\
\hline CF0 & 95.31 & 373.56 & 669.41 \\
& $90.80^{\mathrm{a}}$ & $372.56^{\mathrm{a}}$ & $648.11^{\mathrm{a}}$ \\
CF2 & 64.53 & 348.19 & 666.48 \\
CF4 & 13.61 & 99.96 & 275.67 \\
SPF1 & 11.58 & 28.65 & 67.43 \\
SPF2 & 13.13 & 78.94 & 378.23 \\
\hline
\end{tabular}

First load, five runs

${ }^{\mathrm{a}}$ Second load, five runs

$30 \mathrm{~Hz}$, respectively. These two values for $\mu$ can be combined with $\beta$ of specific flour to calculate the maximal and minimal values of the product $\beta \times \mu$. Clearly, among the selected flours, highest $\beta \times \mu$ product will be that of a corn flour CF1 that is richest in carotenoids (concentration of $33.42 \mathrm{mg} \mathrm{kg}^{-1} \mathrm{TC}$ corresponds to $\beta=17.8 \mathrm{~cm}^{-1}$ ) and lowest modulation frequency $(9 \mathrm{~Hz})$ at which $\mu=7.41 \times$ $10^{-3} \mathrm{~cm}$; hence, $\beta \times \mu=17.8 \mathrm{~cm}^{-1} \times 7.41 \times 10^{-3} \mathrm{~cm}=0.132$, which is indeed smaller than 1 . Since $36 \mathrm{mg} \mathrm{kg}^{-1}$ is the highest concentration of TC among 33 different corn flours, it follows that at the two frequencies used here the condition $\beta \times \mu<1$ is met for all samples. On the other hand, the minimal $\beta \times \mu$ value is the one associated with the highest modulation frequency $(30 \mathrm{~Hz})$ and a flour that contains the lowest TC concentration. The concentration of TC in SPF investigated in this study exceeded that of corn flours. But, even at the highest TC concentration in the sweetpotato flours (approximately $240 \mathrm{mg} \mathrm{kg}^{-1}$ ) and lower modulation frequency $(9 \mathrm{~Hz})$, the validity of criterion $\beta \times \mu<1$ still applies.

\section{Spectrophotometry}

The PA measurements must be calibrated because the PAS is not yet an absolute method for the quantification of TCs in flours. This was accomplished by determining the TC concentration (expressed as $\beta$-carotene) of all corn flours investigated here by means of the validated hexane extraction-spectrophotometric (SP) method at 441$448 \mathrm{~nm} .{ }^{27}$ As far as sweetpotato flours are concerned, total carotenoids were also extracted with hexane and the TC was computed assuming that all absorbance at $448 \mathrm{~nm}$ can be attributed to $\beta$-carotene. ${ }^{28}$

\section{Results}

\section{Size Distribution Analysis}

The average (median) size $d(0.5)$ (or $\left.d_{50}\right)$ of all (measured) flour particles that have passed laser diffractometer is shown in the second column of Table 1 . Ninety percent of flour particles smaller than a number $d(0.9)$ (or $d_{90}$ ) are
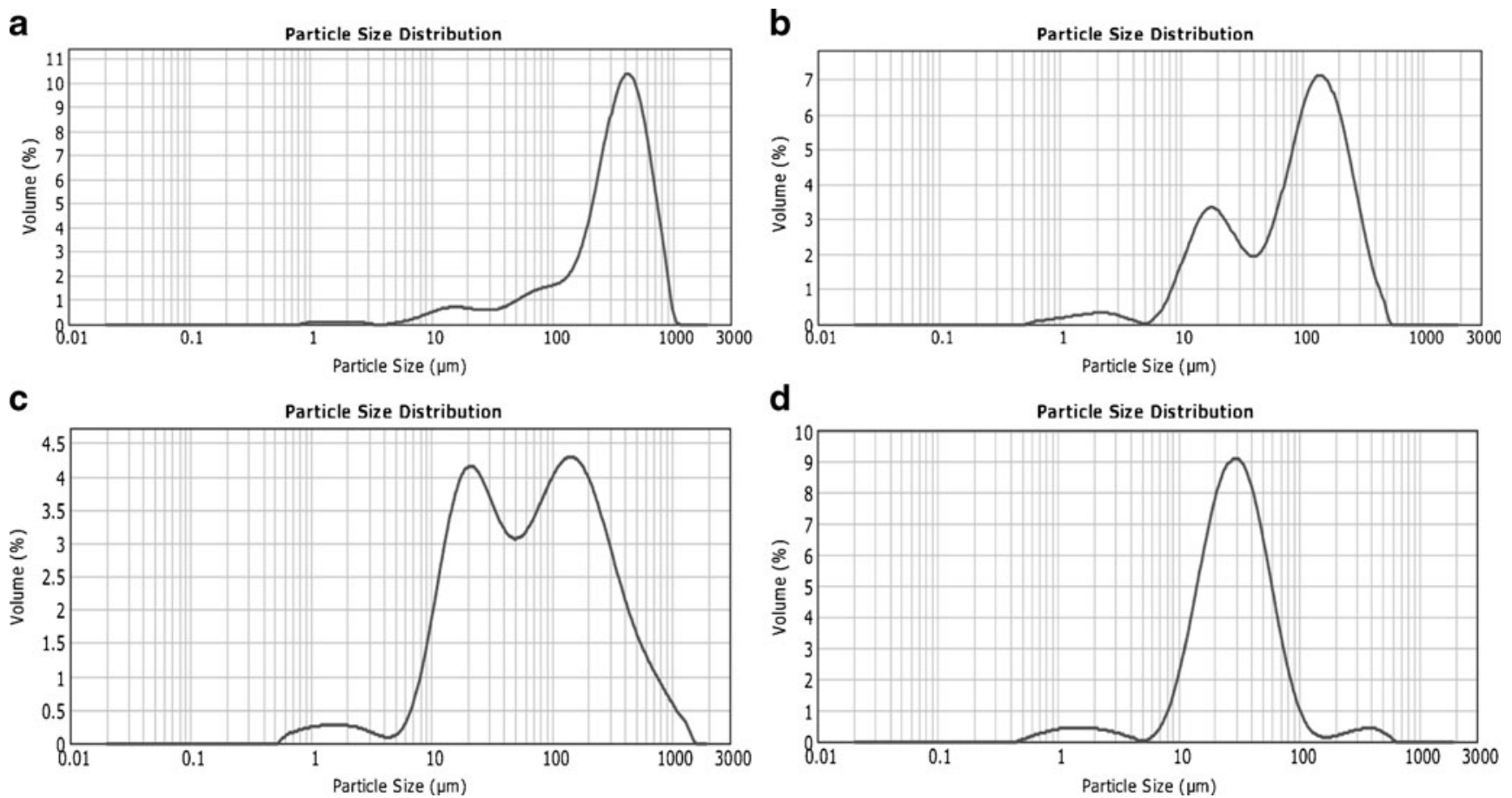

Fig. 1 Particle size distribution of a yellow corn flour CF2 (18.12 $\left.\mathrm{mg} \mathrm{kg}^{-1} \mathrm{TC}\right)$, b yellow corn flour CF4 (10.33 mg kg $\left.{ }^{-1} \mathrm{TC}\right)$, c sweetpotato flour SPF2 (38.8 $\left.\mathrm{mg} \mathrm{kg}^{-1} \mathrm{TC}\right)$, and $\mathbf{d}$ sweetpotato flour SPF1 $\left(0.3 \mathrm{mg} \mathrm{kg}^{-1} \mathrm{TC}\right)$ 
Fig. 2 Verifying the performance of the instrumental setup for PA measurements using: carbon black $\mathrm{CB}$ $\left(N_{f}=14\right)$, corn flours CF1 $\left(N_{f}=\right.$ 15), CF2 $\left(N_{f}=10\right), \mathrm{CF} 3\left(N_{f}=14\right)$, and CF4 $\left(N_{f}=14\right)$. The following quantities have been plotted as a function of the logarithm of the modulation frequency $f: \mathbf{a} \log$ PAS signal $1_{\max }, \mathbf{b} \log \beta \times \mu$. PAS data: $1-3$ measurements; $N_{f}$ number of frequency levels. Total carotenoid concentration in flours is 33.42 (for CF1), 18.12 (for CF2), 0.90 (for CF3), and $10.33 \mathrm{mg} \mathrm{kg}^{-1}$ (for CF4). Instrumental parameters: $\mathrm{cw}$ Ar-ion laser, incident laser power at $488 \mathrm{~nm}$ was 70-74 $\mathrm{mW}$, integration time constant of lock-in amplifier was $1 \mathrm{~s}$
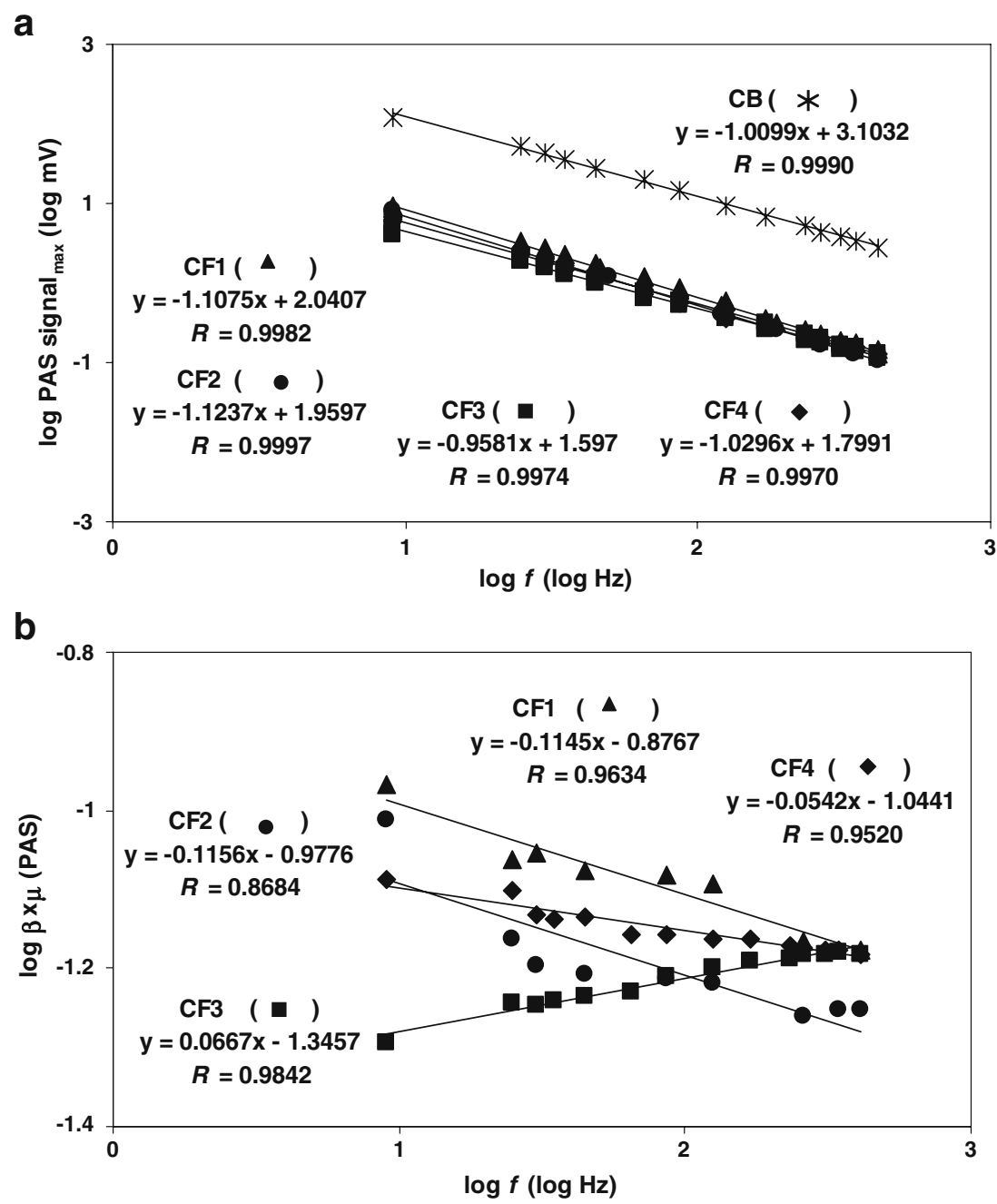

shown in a third column. Likewise, $10 \%$ of the flour particles smaller than $d(0.1)$ (or $\left.d_{10}\right)$ are reported in the first column. The data shown in the three columns are the average of five successive measurements.

The particle size distribution of the finest flour (SPF1) is shown in Figure 1d. There is a single dominant peak and the values for $d(0.1), d(0.5)$, and $d(0.9)$ for this particular load are $11.58,28.65$, and $67.43 \mu \mathrm{m}$, respectively. The shape of the particle size distribution curves obtained from CF2 (Figure 1a) and CF0 (not shown), the most coarse among investigated flours, resembles that of SPF1. On the other hand, particle size distribution for CF4 and SPF2 features two peaks of comparable magnitude as shown in Figure 1b, c, respectively.

\section{Performance of the PA System}

Before beginning with actual PA measurements, it was necessary to verify that the experimental setup is operating properly. Such control measurements were accomplished by studying the frequency dependence $(9$ to $411 \mathrm{~Hz}$ ) of the PA signals obtained from the four corn flours (CF1 to CF4) and the carbon black $(\mathrm{CB})$, a fine powder with high $\beta$ (about $1.1 \times$ $10^{4} \mathrm{~cm}^{-1}$ ). The TC concentration (determined by SP) in four flours is 33.42 (in CF1), 18.12 (in CF2), 0.90 (in CF3), and $10.33 \mathrm{mg} \mathrm{kg}^{-1}$ (in CF4), respectively. These four corn flours were selected because they encompass samples characterized by the low as well as by the high TC concentration.

The frequency dependence of the raw PA signals obtained from the four corn flours and from carbon black powder is shown in Figure 2a. For all flours, the logarithm of the maximal PA signal shown as a function of the logarithm of the modulation frequency $f$ is $a$ straight line with the slope close to -1 , as expected. ${ }^{1}$ The decrease of the PA signal observed at higher frequencies is due to a shorter thermal diffusion lengths and hence more shallow probing depths in the sample. The flour with greater TC concentration produces higher PA signals than the flours with low concentration of TC. The trend observed for $\mathrm{CB}$ is the same as that of flours CF1 to CF4. The linear fits to experimental 
Fig. 3 The correlations between the hundredfold product $\beta \times \mu$ obtained from PAS measurements and total carotenoid (TC) concentration estimated spectrophotometrically in 33 corn flours, concentration range $0.13-36.33 \mathrm{mg} \mathrm{kg}^{-1} \mathrm{TC}$ (3-30 SP analyses per sample), PAS measurements performed within 1-3 different days; $9 \mathrm{~Hz}$ (triangles), 3-28 PAS measurements of a sample; $30 \mathrm{~Hz}$ (circles), 3-21 PAS measurements of a sample. b Eight sweetpotato flours, concentration range $0.3-238 \mathrm{mg} \mathrm{kg}^{-1} \mathrm{TC}$ (1-3 SP analyses per sample); $9 \mathrm{~Hz}$ (triangles), 3-10 PAS measurements of a sample, 1-2 days; $30 \mathrm{~Hz}$ (circles), 3-10 PAS measurements of a sample, 1-3 different days. Mean \pm SD values are presented. Instrumental parameters: $\mathrm{cw}$ Ar-ion laser, incident laser power at $488 \mathrm{~nm}$ was $70-74 \mathrm{~mW}$, the integration constant of the lock-in amplifier was $1 \mathrm{~s}$

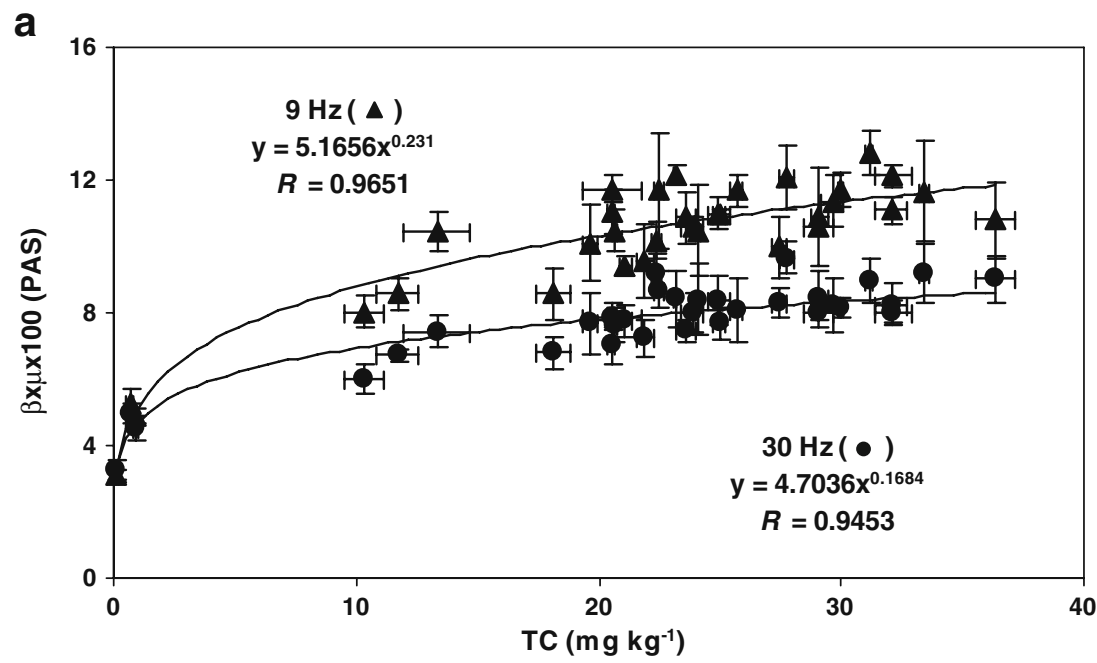

b

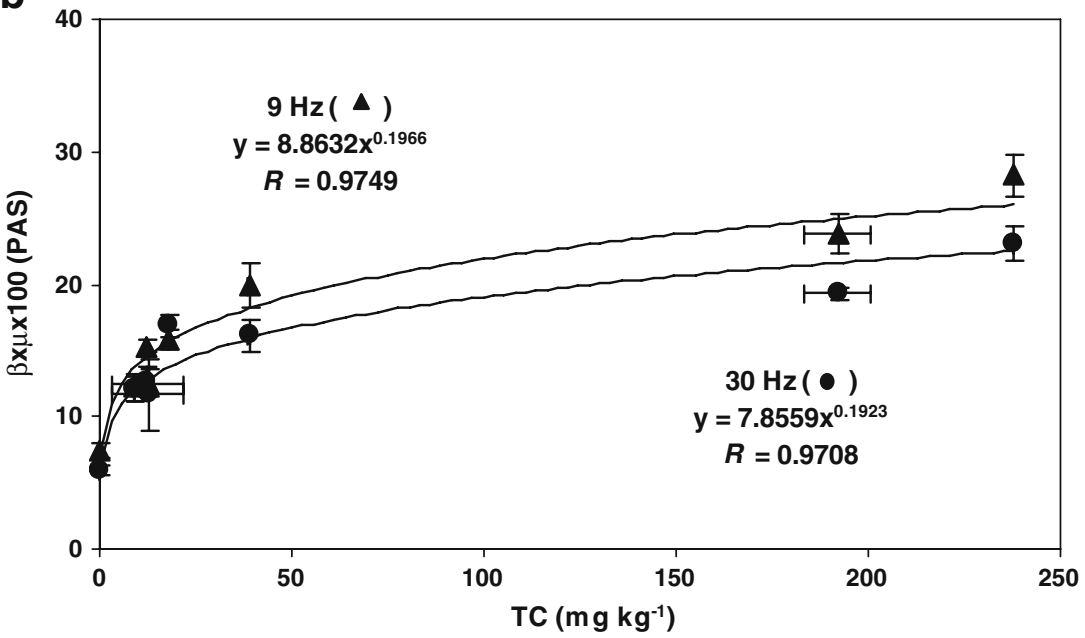

data obtained for all flours are very good with $R$ values exceeding 0.997. The plot showing the logarithm of the $\beta \times \mu$ product (deduced from PA signals) as a function of logarithm of the frequency for $\mathrm{C} 1$ to CF4 flours displays (Figure 2b) the behavior similar to that observed for the logarithm of PA signal (Figure 2a). The only exception is the white corn flour CF3 characterized by its low TC concentration.

The PA Analysis of Total Carotenoids in Flours

Figure $3 \mathrm{a}, \mathrm{b}$ shows the correlations between the product $\beta \times \mu$ obtained via the PA measurements (at 9 and $30 \mathrm{~Hz}$ ) from 33 corn flours and eight sweetpotato flours and the TC concentration of the very same flours measured spectrophotometrically. At $9-\mathrm{Hz}$, thermal diffuson length is about 1.8 times larger than that at $30 \mathrm{~Hz}$, a fact which might prove useful whenever trying to obtain a representative portion of a heterogeneous material such as flour.

The dependence of PA signal on the TC concentration for both corn and sweetpotato flours at both modulation frequencies can be best described by the power functions; the correlation coefficients exceed 0.95; the full dynamic range for corn flours was $0.1-36 \mathrm{mg} \mathrm{kg}^{-1}$ TC as compared with $0.3-238 \mathrm{mg} \mathrm{kg}^{-1}$ TC for sweetpotato flours (see Table 2). Analytically useful linear function was established in a reduced concentration range $\left(0.7-36 \mathrm{mg} \mathrm{kg}^{-1} \mathrm{TC}\right)$ ( $R$ value of $0.86-0.87$ ) for the corn flours. In the first instance, fitting the $\beta \times \mu$ product (that correlates with the amplitude of PA signal) versus TC concentration by a power function may appear to the reader somewhat artificial and not supported by a physical rationale. However, such $\beta \times \mu$ versus TC plots for flours are essential for rapid prediction of total concentration of carotenoids based on the data obtained from the PA measurements. Knowing the general complexity of the PA signal generation in particulate systems, fitting the data is therefore the best that one can do in a given situation. Somewhat lower correlation was found for logarithmic and quadratic fits.

In the case of the sweetpotato flours, three distinct linear concentration regions could be differentiated from 
Table 2 Correlations, $D L$ and RSD data for PAS measurements of corn flours and sweetpotato flours

\begin{tabular}{|c|c|c|c|c|c|c|c|c|c|}
\hline \multicolumn{5}{|c|}{$9 \mathrm{~Hz}$} & \multicolumn{5}{|c|}{$30 \mathrm{~Hz}$} \\
\hline \multicolumn{10}{|c|}{ Corn flours } \\
\hline \multicolumn{10}{|c|}{ Mathematical function in concentration range $\left(\mathrm{mg} \mathrm{kg}^{-1} \mathrm{TC}\right)$} \\
\hline \multirow{6}{*}{$\begin{array}{c}\text { Dynamic range: } \\
0.13-36.33(N=33) \\
\text { power function } \\
R=0.965\end{array}$} & \multicolumn{4}{|c|}{ Linear range } & \multirow{6}{*}{$\begin{array}{c}\text { Dynamic range: } \\
0.13-36.33(N=33) \\
\text { power function } \\
R=0.945\end{array}$} & \multicolumn{4}{|c|}{ Linear range } \\
\hline & \multicolumn{4}{|c|}{$\begin{array}{c}0.66-33.42(N=31) \\
R=0.867 / R S S=24.212\end{array}$} & & \multicolumn{4}{|c|}{$\begin{array}{c}0.66-36.33(N=32) \\
R=0.864 / R S S=9.827\end{array}$} \\
\hline & $\begin{array}{c}\text { Slope } \\
\left(\mathrm{kg} \mathrm{mg}^{-1}\right)\end{array}$ & RSD (\%) & Intercept & RSD (\%) & & $\begin{array}{c}\text { Slope } \\
\left(\mathrm{kg} \mathrm{mg}^{-1}\right)\end{array}$ & RSD (\%) & Intercept & RSD (\%) \\
\hline & 0.192 & 10.7 & 6.074 & 8.0 & & 0.115 & 10.6 & 5.175 & 5.8 \\
\hline & \multicolumn{4}{|c|}{$D L\left(\mathrm{mg} \mathrm{kg}^{-1} \mathrm{TC}\right)$} & & \multicolumn{4}{|c|}{$D L\left(\mathrm{mg} \mathrm{kg}^{-1} \mathrm{TC}\right)$} \\
\hline & \multirow{2}{*}{\multicolumn{4}{|c|}{$\begin{array}{l}0.1 \\
\text { Repeatability }(\%)^{a, c}\end{array}$}} & & \multicolumn{4}{|c|}{0.1} \\
\hline Repeatability (\%) & & & & & \multicolumn{5}{|c|}{ Intermediate precision $(\%)^{b, c}$} \\
\hline \multirow{2}{*}{\multicolumn{5}{|c|}{$0.1-17.1(n=3-12)$}} & \multicolumn{5}{|c|}{$5.3-14.7(n=6-28)$} \\
\hline & & & \multicolumn{7}{|c|}{ Sweetpotato flours } \\
\hline \multicolumn{10}{|c|}{ Mathematical function in concentration range $\left(\mathrm{mg} \mathrm{kg}^{-1} \mathrm{TC}\right)$} \\
\hline \multirow{6}{*}{$\begin{array}{c}\text { Dynamic range: } \\
0.3-238(N=8) \\
\text { power function } \\
R=0.975\end{array}$} & & Linea & & & \multirow{6}{*}{$\begin{array}{c}\text { Dynamic range: } \\
0.3-238(N=8) \\
\text { power function } \\
R=0.971\end{array}$} & \multicolumn{4}{|c|}{ Linear range } \\
\hline & & $\begin{array}{r}9.2-38 \\
R=0.931\end{array}$ & $\begin{array}{l}=5) \\
=5.17\end{array}$ & & & \multicolumn{4}{|c|}{$\begin{array}{c}9.2-38.8(N=5) \\
R=0.693 / R S S=12.10\end{array}$} \\
\hline & $\begin{array}{c}\text { Slope } \\
\left(\mathrm{kg} \mathrm{mg}^{-1}\right)\end{array}$ & RSD (\%) & Intercept & RSD (\%) & & $\begin{array}{c}\text { Slope } \\
\left(\mathrm{kg} \mathrm{mg}^{-1}\right)\end{array}$ & RSD (\%) & Intercept & RSD (\%) \\
\hline & 0.244 & 22.6 & 10.742 & 10.8 & & 0.140 & 60.0 & 11.340 & 15.6 \\
\hline & \multicolumn{4}{|c|}{$D L\left(\mathrm{mg} \mathrm{kg}^{-1} \mathrm{TC}\right)$} & & \multicolumn{4}{|c|}{$D L\left(\mathrm{mg} \mathrm{kg}^{-1} \mathrm{TC}\right)$} \\
\hline & \multicolumn{4}{|c|}{0.3} & & \multicolumn{4}{|c|}{0.3} \\
\hline \multirow{2}{*}{\multicolumn{3}{|c|}{ Repeatability (\%) ${ }^{a}$}} & \multicolumn{2}{|c|}{$\begin{array}{l}\text { Intermediate precision } \\
(\%)^{\mathrm{b}}\end{array}$} & \multirow{2}{*}{\multicolumn{3}{|c|}{ Repeatability (\%) ${ }^{a}$}} & \multicolumn{2}{|c|}{$\begin{array}{l}\text { Intermediate precision } \\
(\%)^{\mathrm{b}}\end{array}$} \\
\hline & & $1.5-8.2(n=3-10)$ & $6.3-8$. & $=8-9)$ & & & & $4.2-23$ & $(n=6-8)$ \\
\hline
\end{tabular}

$D L$ detection limit (based on visual evaluation as the minimum concentration at which the analyte can be reliably detected), $n$ number of independent PAS measurements (in parentheses), $N$ number of sample points (in parentheses), $R$ coefficient of correlation, $R S S$ residual sum of the squares, TC total carotenoids expressed as $\beta$-carotene $\left(\mathrm{mg} \mathrm{kg}^{-1}\right)$

Precision data is given for the whole concentration range investigated: ${ }^{a}$ within-a-run, ${ }^{\mathrm{b}}$ within $2-3$ different days. Intermediate precision data for sweetpotato flours was collected throughout 4 days to 2 months within a run

${ }^{\mathrm{c}}$ For both 9 and $30 \mathrm{~Hz}$

the plots $\beta \times \mu$ versus TC concentration. The first region comprises the TC concentrations lower than $18 \mathrm{mg} \mathrm{kg}^{-1}$ TC and the second those not exceeding $40 \mathrm{mg} \mathrm{kg}^{-1}$ (see Table 2). The third region extends even up to $240 \mathrm{mg} \mathrm{kg}^{-1}$ $\mathrm{TC}$, indicating that sweetpotato flours can be analyzed accross a much wider concentration range of carotenoids than corn flours. The regression line $(R=0.93-0.95)$ in the $17.8-238 \mathrm{mg} \mathrm{kg}^{-1}$ region might be used to analyze high TC sweetpotato flours. However, in this case, the calibration sensitivity is markedly lowered which may jeopardize the accuracy of the results.

Low $D L$ values $\left(0.1\right.$ and $\left.0.3 \mathrm{mg} \mathrm{kg}^{-1} \mathrm{TC}\right)$ for both corn and sweetpotato flours provide the evidence for a high sensitivity achievable in PA analyses.

In general, the precision of the regression line parameters obtained for corn flours was better than that for sweetpotato flours.

The analytical performance of PA system at both modulation frequencies is summarized in Table 2. The calibration sensitivity obtained at $9 \mathrm{~Hz}$ for both corn and sweetpotato flours is almost twice as high as that at $30 \mathrm{~Hz}$. Likewise, precision of regression line paramaters at $9 \mathrm{~Hz}$ was higher than at $30 \mathrm{~Hz}$. At the two selected modulation frequencies, no correlations between the repeatability, the intermediate precision data, and the concentration of TC were found for corn flours. In addition, the repeatabilities at 9 and $30 \mathrm{~Hz}$ were comparable: $0.1-17.1 \%$ for corn flours and $1.4-9.1 \%$ for sweetpotato flours. Calculated intermediate precision RSD values for corn and sweetpotato flours were $5.3-14.7 \%$ and $4.2-23.0 \%$, respectively.

\section{Conclusion}

Overall, the outcome of control PA measurements (Figure 2a, b) provides a convincing amount of experimental evidence for a proper functioning of the experimental setup. This has allowed one to proceed with the quantitative PA studies of TC concentration in corn and sweetpotato flours.

The concentration of TC in the examined flours that can be reliably analyzed spans the range from $1 \mathrm{mg} \mathrm{kg}^{-1}$ (in corn flours) and from $9 \mathrm{mg} \mathrm{kg}^{-1}$ (in sweetpotato flours) to $40 \mathrm{mg} \mathrm{kg}^{-1}$ (in both cases). The lowest detectable TC concentration in corn and sweetpotato flours was 0.1 and $0.3 \mathrm{mg} \mathrm{kg}^{-1}$, respectively. Data displayed in Table 2 also shows that for analysis of both corn and sweetpotato flours, in terms of higher calibration sensitivity, $9-\mathrm{Hz}$ modulation frequency is more favorable than $30 \mathrm{~Hz}$.

The RSD values (up to 20\%) indicate acceptable precision of PAS when this technique is applied for direct assaying the TC concentration in complex, heterogeneous, powdered samples such as flours.

Inspection of data presented in Table 1 and in Figures 1 and 3 may substantiate the idea that the PA signal is lower in the case of more coarse flours. This holds true for the 
most coarse grains CF0 and CF2 (with a mean diameter of ca. $400 \mu \mathrm{m}$ ) compared with CF4, as well as for SPF2 versus the finest SPF1 sample (mean diameter of ca. $30 \mu \mathrm{m}$ ).

The investigation described here can be regarded as a first large-scale PA study of TC in (true) realistic flours. As such, it is a logical consequence of the PA feasibility study performed in the past within the frame of Harvest Plus Challenge Program (coordinated by the Centro Internacional de Agricultura Tropical (CIAT) Cali, Columbia and the International Food Policy Research Institute (IFPRI), Washington, DC, USA), on the model systems (white corn flours that were deliberately colored with a varying amount of synthetic beta carotene). ${ }^{29,30}$ The application of PA spectroscopy for the quantification of TC in flours requires no use of toxic chemicals; in addition, the entire analysis is completed quickly. No problems associated with the irreproducible PA cell loadings were encountered with the present setup. The PA screening of solely pro-vitamin A carotenoids in the corn flour is not possible unless beta carotene is separated from lutein and zeaxanthin (two major carotenoids in corn flour) prior to the PA measurements. On the other hand, there are exactly these two vitamin A-inactive carotenoids that are important to human health due to their demonstrated positive action against cataract and the macular degradation. ${ }^{31}$

Open Access This article is distributed under the terms of the Creative Commons Attribution Noncommercial License which permits any noncommercial use, distribution, and reproduction in any medium, provided the original author(s) and source are credited.

\section{References}

1. A. Rosencwaig, Photoacoustics and Photoacoustic Spectroscopy (Wiley, New York, 1996)

2. D. Almond, P. Patel, Photothermal Science and Techniques (Chapman and Hall, London, 1996)

3. K.H. Michaelian, Photoacoustic Infrared Spectroscopy, in A Series of Monographs on Analytical Chemistry and Its Applications, vol 159, ed. by J.D. Winefordner (Wiley, Hoboken, 2003)

4. S.P. Belton, A.M. Saffa, R.H. Wilson, Analyst 112, 1117-1120 (1987)

5. D. Bicanic (ed.), Special Issue on Photoacoustic and Photothermal Methods in the Life Sciences-Selection of Upcoming Issues. Instrum. Sci. Technol. 34, 1-234 (2006)

6. T. Schmid, Anal Bioanal Chem 384, 1071-1086 (2006)

7. D. Bicanic, S. Luterotti, M. Becucci, V. Fogliano, P. Versloot, J Phys IV France 391, 825-828 (2005)
8. D. Bicanic, V. Fogliano, S. Luterotti, S. Swarts, G. Piani, G. Graziani, J Sci Food Agric 85, 1149-1153 (2005)

9. D. Bicanic, M. Anese, S. Luterotti, D. Dadarlat, J. Gibkes, M. Lubbers, Rev Sci Instr 74, 687-689 (2003)

10. S. Luterotti, D. Bicanic, K. Jandragić, Food Chem 108, 316-321 (2008)

11. D.B. Rodriguez-Amaya, M. Kimura, HarvestPlus Handbook for Carotenoid Analysis, HarvestPlus Technical Monograph 2 (IFPRI and CIAT, Washington, 2004)

12. M. van Hal, Food Rev Int 16, 1-37 (2000)

13. U. Kidmose, R.Y. Yang, S.H. Thilsted, L.P. Christensen, K. Brandt, J Food Comp Anal 19, 562-571 (2006)

14. C.C. Teow, V.D. Truong, R.F. McFeeters, R.L. Thompson, K.V. Pecota, G.C. Yencho, Food 103, 829-838 (2007)

15. A. Cortes-Gomez, J.L. Jimenez Perez, A. Cruz Orea, E. Martin Martinez, Int J Thermophys 27, 1274-1280 (2006)

16. J.J. Alvarado-Gil, F. Zelaya Angel, F. Sanchez-Sinencio et al., J Food Sci 60, 438-442 (1995)

17. O. Delgado-Vasallo, J.L. Pena, E. San Martin Martinez, A. Calderon, G. Pena Rodriguez, M.R. Jaime Fonseca, E. Marin, Anal Sci 19, 599-602 (2003)

18. O. Dóka, D.D. Bicanic, M.H. Dicko, M.A. Slingerland, J Agric Food Chem 52, 2133-2136 (2004)

19. V. Anderberg, Near Infrared Spectroscopy for Measuring Optical Properties in Flour and Grain, Master's Thesis (Faculty of Engineering, Lund University, Lund, 2009)

20. ICH Harmonized Tripartite Guideline, Validation of Analytical procedures: Text and Methodology Q2(R1), Current Step 4 version (International Conference on Harmonisation of Technical Requirements for Registration of Pharmaceuticals for Human Use, Geneva, 2005)

21. R.S. Davidson, D. King, Anal Chem 56, 1409-1411 (1984)

22. T.A. El-Brolosy, S. Negm, H. Talaat, J Chem Sci 110, 181-184 (2008)

23. P. Belton, R.H. Wilson, A.M. Saffa, Anal Chem 59, 2378-2382 (1987)

24. P.S. Belton, S.F. Tanner, Analyst 108, 591-596 (1983)

25. M. Božikova, Res Agr Eng 49, 157-160 (2003)

26. T.R.A. Magee, T. Bransburg, J Food Eng 25, 223-232 (1995)

27. S. Luterotti, K. Kljak, Acta Chim Slov (2010) (in press)

28. N.E. Craft, J.H. Soares Jr., J Agric Food Chem 40, 431-434 (1992)

29. D. Bicanic, R. Spruijt, O. Dóka et al., Direct Detection of BetaCarotene in the Model Mixtures of Pre-Cooked White Corn Flour: The Multi Methods Approach, in Proceedings of the 2008 Joint European Congress - 4th Central European Congress of Food/6th Croatian Congress of Food Technologists, Biotechnologists and Nutritionists, Cavtat, Croatia, vol. 2, 175-191 (Food Technologists, Biotechnologists and Nutritionists Society, Zagreb, 2008)

30. D. Bicanic, Detection of Specific Carotenoids in Selected Flour Samples by Means of the Photoacoustic, Photothermal and Other Methods That Require Little or No Sample Preparation. Report prepared for Harvest Plus Challenge Program, Washington DC, Agreement \# 8028, 2007)

31. D.B. Rodriguez-Amaya, A Guide to Carotenoid Analysis in Foods (International Life Sciences Institute (ILSI) Press, Washington, 2001) 